\title{
Dermatologie
}

\section{KBV meldet überdurchschnittliche Honorarzuwächse}

\author{
Im Bundesdurchschnitt sind die Honorarumsätze je Hautarztpraxis im ersten Halbjahr 2011 um 7,2\% auf \\ knapp $97.000 €$ gestiegen. Der Gewinn ist in gleichem Ausmaß auf $46.406 €$ angewachsen. Dies geht aus dem \\ jetzt erstmals von der KBV vorgelegten Honorarbericht gemäß GKV-VStG hervor. Aktuelle Zahlen zur Entwick- \\ lung der Arzthonorare wird es künftig quartalsweise, differenziert nach KVen und Fachgruppen, geben.
}

W ie bei allen anderen Arztgruppen auch, weisen die Umsatzveränderungen auch bei Dermatologen eine breite Spreizung auf. Honorarverluste in Höhe von 4,3\% gab es in der KV Hamburg; sie beruhen auf Überzahlungen im ersten Halbjahr 2010, die in den Folgeperioden kompensiert wurden. Gleichwohl bleiben die Hautärzte dort mit $111.200 €$ Umsatzspitzenreiter in Deutschland. Die im Vergleich zu anderen Facharztgruppen leicht überdurchschnittliche Honorarsteigerung ist nach Angaben der KBV größtenteils auf die Balneophototherapie zurückzuführen, die seit dem 1. Oktober 2010 eine GKV-Leistung ist. Der Umsatzzuwachs verteilt sich auf die KVen unterschiedlich: Die stärksten Zuwächse verzeichnen Hautärzte in Bremen mit 22,1\%, in Schleswig-Holstein mit $19,8 \%$, in Rheinland-Pfalz mit $15,8 \%$ und in Sachsen mit 15,1\% (Tabelle 1).

Auch die Durchschnittsumsätze je Praxis variieren je nach Standort erheblich. Weit unter dem Bundesdurchschnitt von knapp $97.000 €$ bleiben die Hautärzte in den KVen Berlin (73.400 €), Thüringen (knapp $82.000 €)$ Brandenburg $(82.500 €$ ) und Rheinland-Pfalz mit knapp $82.000 €$.

Mit 33,27 € gehören Hautärzte zu den Fachgruppen mit den niedrigsten Fallwerten: 33,27 $€$, die im Bundesdurchschnitt um $6,3 \%$ gestiegen sind. Dabei schwanken die Fallwerte zwischen $27,18 €$ in Thüringen und 38,32 € in Baden-Württemberg und Bayern.

Den bundesdurchschnittlichen Praxisgewinn im ersten Halbjahr 2011 beziffert die KBV auf $46.400 €, 7,2 \%$ mehr als im gleichen Vorjahreszeitraum. Die Derma- tologen liegen damit im Fachgruppenvergleich auf dem Niveau der Allgemeinmediziner/hausärztlichen Internisten, der Orthopäden, der Chirurgen und der Urologen. Deutlich über diesem Niveau liegen die internistischen Schwerpunkte, insbesondere Gastroenterologen und Onkologen sowie Kinderärzte. Weit unter dem Durchschnitt liegen Neurologen und Psychiater (knapp 42.000 und knapp $38.000 €$ ) sowie Psychotherapeuten mit $25.600 €$.

Helmut Laschet

\begin{tabular}{|c|c|c|c|c|}
\hline $\begin{array}{l}\text { Kassenärztliche } \\
\text { Vereinigung }\end{array}$ & $\begin{array}{l}\text { Honorarumsatz } \\
\text { je Arzt in } € \\
\text { im 1. Hj. } 2011\end{array}$ & $\begin{array}{l}\text { Veränderung } \\
\text { gegenüber } \\
\text { 1. Hj. } 2010\end{array}$ & $\begin{array}{l}\text { Honorarumsatz } \\
\text { je Behandlungsfall } \\
\text { in } € \text { im 1. Hj. } 2011\end{array}$ & $\begin{array}{l}\text { Veränderung } \\
\text { gegenüber } \\
\text { 1. Hj. } 2010\end{array}$ \\
\hline Schleswig-Holstein & 105.278 & $19,8 \%$ & 35,19 & $12,5 \%$ \\
\hline Hamburg & 111.200 & $-3,7 \%$ & 33,89 & $-4,3 \%$ \\
\hline Bremen & 102.100 & $22,1 \%$ & 32,12 & $19,6 \%$ \\
\hline Niedersachsen & 98.293 & $12,2 \%$ & 32,00 & $9,9 \%$ \\
\hline Westfalen-Lippe & 109.601 & $12,3 \%$ & 32,30 & $10,7 \%$ \\
\hline Nordrhein & 84.777 & $2,7 \%$ & 30,32 & $2,8 \%$ \\
\hline Hessen & 104.648 & $4,1 \%$ & 33,08 & $5,3 \%$ \\
\hline Rheinland-Pfalz & 81.717 & $15,8 \%$ & 31,59 & $13,0 \%$ \\
\hline $\begin{array}{l}\text { Baden-Württem- } \\
\text { berg }\end{array}$ & 109.126 & $7,6 \%$ & 38,32 & $6,6 \%$ \\
\hline Bayern & 92.610 & $0,5 \%$ & 38,32 & $2,3 \%$ \\
\hline Berlin & 73.462 & $14,0 \%$ & 28,96 & $9,3 \%$ \\
\hline Saarland & 98.158 & $6,1 \%$ & 36,07 & $3,1 \%$ \\
\hline Mecklenburg-Vorp. & 103.456 & $0,2 \%$ & 32,80 & $-0,7 \%$ \\
\hline Brandenburg & 82.532 & $2,3 \%$ & 23,60 & $1,8 \%$ \\
\hline Sachsen-Anhalt & 94.180 & $9,6 \%$ & 30,24 & $8,5 \%$ \\
\hline Thüringen & 81.928 & $5,3 \%$ & 27,18 & $4,6 \%$ \\
\hline Sachsen & 108.989 & $15,1 \%$ & 32,38 & $12,6 \%$ \\
\hline Bund & 96.903 & $7,2 \%$ & 33,27 & $6,3 \%$ \\
\hline
\end{tabular}

